\title{
О МЕТОДИКЕ ФОРМИРОВАНИЯ ЕДИНСТВА ТРАДИЦИЙ И ИННОВАЦИЙ В ПОДГОТОВКЕ БУДУЩИХ УЧИТЕЛЕЙ-ФИЛОЛОГОВ
}

\author{
Бабаева Зарина Сайфуллаевна, \\ соискатель кафедры русского языка и методики преподавания, \\ Ташкентский государственный педагогический университет имени Низами, \\ 2. Таикент, Узбекистан
}

DOI: https://doi.org/10.31435/rsglobal_ws/28022020/6936

\section{ARTICLE INFO}

Received: 20 December 2019

Accepted: 11 February 2020

Published: 28 February 2020

\section{KEYWORDS}

game technique,

integration of the environment of an educational institution,

the method of psychological modeling of tasks,

advanced technologies and

management methods,

psychological and pedagogical

subtlety,

private,

modular and systemic innovations.

\begin{abstract}
The study of domestic philological education as a holistic and systemic phenomenon involves its study, both from the point of view of historical retrospective and in the context of modern innovative settings. Meanwhile, the scientific field related to the study of the interaction of traditions and innovations in the evolution of domestic philological education has not received due understanding by now. Within the framework of the indicated problem, questions arise, the solution of which in modern conditions has special acuteness and topicality.

What are the trends and dynamics of changes in the interaction of traditional and new experience in the development of domestic philological education? What factors influence the nature of the interaction of traditions and innovations in the development of the theory and practice of domestic philological education? What does analysis and understanding of the interaction of traditions and innovations in the historical past of Russian philological education give to assess its current state and, no less important, to predict its future development? The list of these questions indicates the seriousness and scope of the study.

The dynamism of global changes in the world, the change in the economic and socio-cultural patterns in the country contributed to the fact that higher education had to flexibly respond to the current situation in the training of personnel.
\end{abstract}

Citation: Бабаева 3. C. (2020) O Metodike Formirovaniya Edinstva Tradicij i Innovacij v Podgotovke Budushchih Uchitelej-Filologov. World Science. 2(54), Vol.2. doi: 10.31435/rsglobal_ws/28022020/6936

Copyright: (C) 2020 Бабаева 3. С. This is an open-access article distributed under the terms of the Creative Commons Attribution License (CC BY). The use, distribution or reproduction in other forums is permitted, provided the original author(s) or licensor are credited and that the original publication in this journal is cited, in accordance with accepted academic practice. No use, distribution or reproduction is permitted which does not comply with these terms.

Актуальность. Всестороннее развитие Узбекистана, повышение уровня и качества жизни народа в первую очередь неразрывно связаны с широким внедрением в практику достижений науки, высоких технологий, современных инновационных разработок. И именно с этой целью было организовано Министерство по инновационному развитию Республики Узбекистан, перед которым стоят задачи по реализации важнейших проектов не только в экономической сфере, но и в жизни всего общества. Основным курсом развития государства становится переход на путь инновационного развития, направленного на коренное улучшение всех сфер жизни государства и общества, когда бизнес-деятельность организуется на основе инновационных, современных подходов, передовых технологий и методов управления.

В основе проведения занятий по изучению разных вопросов и специальных занятий по профессионально-психологической подготовке лежит разработанный нами метод психологического моделирования задач, условий $и$ трудностей профессиональнопедагогической деятельности студентов.

Есть два взаимосвязанных пути моделирования: 
Первая часть метода - приближение внешних условий занятий к реальным условиям профессиональных педагогических действий, т.е. воспроизводство внешней картины их. Это позволяет обучающимся студентам воспринимать трудную обстановку и ощущать себя участниками реальных событий. Внешняя картина учебной обстановки, похожая на реальную, создается выполнением (проигрышем) профессиональных действий, усложнением задач, созданием внешних трудностей их решения, выбором трудных условий времени, места, освещенности, имитацией психологически действующих на сотрудников, различных факторов (например: созданием помех, введением в обстановку противоборствующих сил, фактическим использованием средств индивидуальной защиты, спецсредств, оружия для решения филологических учебных задач и т.п.).

Вторая часть метода - приближение внутренних условий (психических состояний, переживаний, трудностей, умственного и эмоционально-волевого напряжения, страха, тревожности и др.) к тем, которые будут характерны для реальной экстремальной обстановки (воспроизводство сущностной реальной обстановки). Для этого требуется насыщение занятий трудными задачами (в условиях инновационного образования), предполагающими повышенную ответственность, понимание и правильную оценку обстановке; сложными препятствиями, «элементами риска», «опасности», «внезапности», «необычности», «противодействия преступного элемента», самостоятельности;

- психологическими проблемами;

- необходимо также быстрое изменение обстановки, лимитирование времени, интенсивное наращивание трудностей, длительности больших нагрузок и др.

Моделирование реальных, психологически трудных условий деятельности успешно, если для этого используются во взаимосвязи и необходимых пропорциях оба пути. Знакомя обучающихся с сильно воздействующими на психику факторами, нужно иметь в виду, что трудности закаляют одних, но могут надломить других. Нерасчетливое запугивание трудностями способно подтолкнуть некоторых молодых студентов - будущих педагогов к выводу об ошибочности выбора профессии, желанию отстраниться. Последовательность в ознакомлении со сложностями работы должна осуществляться с постепенным нарастанием их, при учете выработанной профессионально-психологической устойчивости обучаемых педагогического вуза, сопровождаться предупреждениями и советами руководителя филологических занятий.

Формами специальных занятий по профессионально-психологической подготовке, оправдавшими себя на практике, и рекомендованные в нашей модели, являются филологические лекции, тактические летучки, семинары, практические занятия, психологический тренинг, психотехнические филологические игры, тактические игры, просмотр специальных фильмов филологической направленности. Практические формы обучения составляют до $60 \%$ учебного времени, отводимого на эту подготовку.

При разработке методики, учитывали, что моделирование реальных условий требует создания хорошей материальной базы:

- специального учебного места (например, модели перекрестка в натуральную величину с находящимися по углам жилым домом, общественным местом, магазином, школой, лицеем, колледжем, вузом и пр.);

- площадки для эмоционально-волевых упражнений (с сооружениями, использование которых вызывает у обучающихся волнение, тревогу, страх, опасения и одновременно необходимость проявления воли, умения овладеть собой и заставить сделать то, что требует руководитель занятий, - это, например, различные лестницы, ямы для перепрыгивания и перехода по доске, качающиеся мостки и др.);

- учебных комнат, оборудованных под учебное заведение, магазин, холл банка и пр.;

- наборов специальных видеофильмов, слайдов, фотоальбомов и пр.

Хорошо использовать сооружения на территории специально на территории специального образовательного учреждения.

Многие занятия, проводимые по игровой методике, проходят успешнее при участии имитаторов - специально подготовленных руководителями занятий, которые в ходе занятий имитируют поведение и действия других лиц. 
Психолого-педагогическая тонкость - в строгом подборе учебного материала, условий и заданий, которые бы максимально активизировали именно те психологические и психофизиологические процессы и механизмы, которые лежат в основе определенных педагогических компетенций.

Существует много тренингов по развитию профессиональной памяти: запоминание инструкций, адресов, фамилий, номеров автомашин, телефонов, паспортных данных, дословных выражений собеседника, деталей сообщаемых фактов и др. При разработке методики учитывали, что студентов вуза можно «тренировать» с помощью особых заданий на профессиональную внимательность и ее отдельные свойства (интенсивность, концентрацию, широту, переключаемость, распределение, устойчивость), развить образные представления и их мысленный анализ, мышление, скорость оценки обстановки, элементы психологической наблюдательности и другие. Занятия должны проводиться и на местности, например, по определению расстояний до разных объектов, высот объектов, скорости движения транспортных средств по дороге, интервалов времени, различных звуков, запахов и других.

Результаты исследования. Одна из новых форм развития психологических качеств, рассмотренная при разработке методики - профессиональные психотехнические игры. Они проводятся в группах, чаще всего попарно, продолжительностью 10-20 минут, например: игра под названием «Немой». Одному из обучающихся («немому») выдается текст размером с полстраницы с описанием криминальной или житейской ситуации. Его задача - жестами и мимикой (не издавая звуков) передать второму содержание текста. Задача второго - понять, а потом рассказать, что он понял. Цель игры: приучить первого рационально и выразительно пользоваться мимикой и жестами, а второго - следить за партнером по общению, его жестами и мимикой, чтобы потом в деловом общении с гражданами использовать эту привычку и слушать не только слова. Проводится разбор, за которым игра повторяется с переменой обязанностей и на новом текстовом материале.

Ещё один пример игры - «Рефлексивное мышление». Высвечивается на экране (при помощи проектора) карта одного из городов Узбекистана (или любой другой точки мира). Задание всем: «Bbl с напарником приехали в малознакомый город и потеряли друг друга в толпе. Куда вы направитесь, чтобь встретиться? Постарайтесь понять, как будет рассуждать другой и куда он пойдет икать вас». Сидящие рядом принимают независимо друг от друга решение, а затем, огласив его, объясняют, на чем оно основано. Возможны варианты игры: сотрудник правоохранительных органов и убежавший от него правонарушитель или угонщик автомашины, вор, спрятавший похищенное в тайнике (квартира, приусадебный участок и др.), новый преподаватель в (городской, сельской) школе и т.п.

При разработке методики отрабатывали владение формирования у студентов умения владеть собой. Выдержка и самообладание во многом зависят от мало меняющихся психофизиологических особенностей человека (возбудимости, эмоциональной реактивности, тревожности, устойчивости к риску, уравновешенности нервных процессов - одного из свойств типа нервной системы человека и др.). Но как качество личности оно обусловлено и многим другими принципами, в частности умением владеть собой. Это умение - продукт знания обучаемых методов самоуправления своими состояниями и отработки этих приемов до автоматизма. К числу методов, которым необходимо обучать студентов, относятся: самоприказы и самовнушения.

Практические исследования модели обучения с помощью инновационных педагогических технологий показывают, что на плохо, недостаточно подготовленного к решению задач в различных ситуациях студента, она и присущие им факторы сказываются отрицательно: вызывают растерянность, нерешительность, страх, ухудшение оценки обстановки, сообразительности, находчивости, наблюдательности, работы памяти, скорости реакций, ослабление самоконтроля и самоуправления, учащение и углубление ошибок, снижение точности действий и др.

Современные специалисты выделяют частные, модульные и системные инновации. Преподаватель может осуществлять частные инновации, они меняют локальный характер, выстраивается определенная дидактическая и воспитательная система. Модульные инновации влекут за собой комплекс нововведений: содержание, технологии, сущность, принципы и др. В итоге возникает потребность изменить всю систему: воспитание, образование, управление и др.

Анализ огромного количества инноваций в системе обучения позволяет выделить отдельные их типы. Инновация в содержании - содержание предмета должно соответствовать духу 
времени, новым законам и законодательствам, носить практико-ориентированный характер. Инновации в технологии обучения - появление новых методических приемов, которые ранее не использовались. В первую очередь это связано с проведением деловых игр и различных форм интерактивного обучения. Инновации в управляющей системе - появление новых должностей, изменение системы методической работы преподавателей и т.д. Инновации в воспитательной работе представляют важный процесс целенаправленного воздействия на личность с целью формирования положительных человеческих черт. Это способствует становлению личности, которая уважает права человека, законы страны и исполняет предписания права.

Интеграция среды образовательного учреждения (вуза и колледжа) осуществляется на методологическом, структурно-функциональном и содержательном уровнях. Основу методологического уровня интеграции образовательной среды составляет синтез системного, средового, деятельностного, эколого-психологического, компетентностного подходов. Структурно-функциональный уровень интеграции образовательной среды характеризуется взаимодействием образовательных сред разных уровней организаций и различной функциональной принадлежности. Содержательный уровень интеграции образовательной среды организован как объединение вариативных возможностей обучающих и развивающих ресурсов, связи и отношения между которыми имеют кооперирующий характер.

Внедрение инновационных педагогических технологий как процесс постоянного развития может эффективно осуществляться при использовании потенциала средового подхода. Научно-методическое сопровождение процесса внедрения инновационных педагогических технологий в условиях интегративной образовательной среды включает мотивационно-целевой (определение приоритетных технологий, развитие мотивации преподавателей, проведение мониторинга); организационно-технологический компонент (формы научно-методической деятельности); аналитический (эффективное использование инновационных педагогических технологий) и т. д.

В слабо подготовленных группах часто возникают нездоровые и пессимистические настроения, настроения недовольства, отрицательные мнения, ослабление дисциплины, конфликты во взаимоотношениях, паника и т.п.

И, напротив, на хорошо подготовленного студента к решению задач в различных ситуациях и условиях они сказываются положительно, способствуя мобилизации сил и возможностей, обострению у него чувства долга, ответственности и решимости, вызывают внутренний подъем, даже азарт, энергичность и активность, настойчивость и упорство, деятельностный максимализм (страстное стремление добиться самого высокого результата), повышенную бдительность, внимательность, наблюдательность, быструю и четкую работу мысли, готовность к любым неожиданностям и быстрым реакциям, смелость, устойчивость к временным неудачам и др. Качество действий по сравнению с нормой даже повышается, что относится и к хорошо подготовленным группам.

Правильная обученность играет огромную роль в поведении человека в экстремальных ситуациях, определяя приоритетные ценности поведения, стремление к следованию определенным нормам и выбору средств и способов поведения.

Педагогическая сформированность будущего педагога может находиться на высоком, среднем или низком, примитивном уровне (педагогическая запущенность) и выступает базовой основой его поведения в любых экстремальных правовых ситуациях. С достигнутым уровнем он входит в любые жизненные ситуации, проявляя имеющиеся у него базовые предпосылки к тому, якобы справиться с возникшими трудностями разного рода.

Низкий уровень педагогической сформированности личности студента, педагогическая запущенность, невоспитанность, примитивное понимание жизни, доминирование в его личности низменных потребностей, эгоизм, индивидуализм, привычка к праздности, отсутствие трудолюбия, требовательности к себе - зияющие «трещины» в личностной платформе. Смелость, мужество, устойчивость к опасностям и трудностям экстремальных ситуаций - это проявление обще педагогической сформированности человека, его личности - фундамент возможности встречать и переносить любые трудности, невзгоды, личные кризисы (которых вовсе избежать нельзя), умение «держать удар», не отчаиваться при неудачах, а добиваться своих целей в любых обстоятельствах. Без достаточно высокого уровня педагогической сформированности личности будущего педагога не может быть успешной и его специальная подготовленность. Поэтому 
последняя, как и успех действий в экстремальных ситуациях, зависит от всей системы педагогической работы с персоналом каждого учебного заведения.

Вывод. Многочисленные исследования (в том числе и наша опытно-экспериментальная работы) показали, что студенту в процессе профессиональной педагогической учебы необходимо:

- твердо и точно знать, с какими ситуациями он, возможно, будет сталкиваться, в чем их особенности, какие трудности ожидают его;

- в совершенстве знать и уметь выполнять обычные профессиональные педагогические действия, не ухудшая их качество под влиянием любых факторов и трудностей, свойственных профессиональным ситуациям;

- дополнительно обладать безукоризненно отработанными умениями выполнять особые действия, адекватные специфике разных типов ситуаций;

- обладать развитыми качествами и умением действовать без растерянности и успешно в условиях непредвиденности, впервые встретившихся ситуаций и факторов, обладать «привычкой к непривычному»;

- быть специально обученным действиям по обеспечению личной безопасности в профессиональных ситуациях;

- обладать повышенной устойчивостью, чтобы в любых условиях не снижать качество действий, выполнять их смело, гибко, уверенно, при полном самообладании;

- быть способным настойчиво, невзирая на трудности, наступательно, гибко, умело реализовывать свои намерения и достигать цели.

Наличие подготовленности, обладающей перечисленными признаками, оказывает широкое положительное влияние на личность будущего педагога, его профессионализм и действия. Он будет чувствовать себя намного увереннее, чем неподготовленный. Сознание же собственной неподготовленности, неумелости - источник трусости и волнений там, где для них нет оснований. Подготовленный студент лучше разбирается в особенностях возникающих юридических ситуаций, более правильно оценивает их, предвидит развитие событий, что делает возникающие трудности понятными, ожидаемыми, исключает если не все, то многие неожиданности, не позволяет застать себя врасплох и действовать впопыхах. Подготовленный студент меньше нервничает, волнуется, действует с самообладанием, расчетливо, допускает меньше ошибок и промахов и не создает дополнительные трудности себе. Более того, он положительно влияет на других. Профессионализм и уверенные действия его в правовом аспекте, благотворно сказываются на психическом состоянии и действиях даже слабо подготовленного другого студента.

\section{ЛИТЕРАТУРА}

1. Одинаев И.У. Интенсивные технологии обучения русскому языку в системе высшего образования: Дисс. ... канд. пед. наук - Душанбе, 2013. - 168 с.

2. Олешков М.Ю. Современные образовательные технологии: учебное пособие. - Нижний Тагил: НТГСПА, 2011. - С. 6-12.

3. Орлова Т.В. Новые подходы к перспективному планированию развития школ инновационного типа. - М.: Сентябрь, 1998. - 208с.

4. Поляков С.Д. В поисках педагогической инноватики. - М.МГПИ, 1993. -65 с.

5. Рахимиманд М. Использование инновационных методов обучения в совершенствовании успеваемости студентов вуза (на примере ВУЗов Исламской Республики Иран): Дисс. ... канд. пед. наук. - Душанбе, 2013. - 155c.

6. Сластёнин В.А. Педагогика: Учебное пособие / В.А. Сластёнин, И.Ф. Исаев, Е.Н. Шиянов / Под ред. В.А. Сластёнина. - М.: Академия, 2007. - С. 407.

7. Сластенин В.А., Подымова Л.С. Педагогика: инновационная деятельность. - М.: Изд-во Магистр, 1997.-223c.

8. Спирин Б.Ф. Педагогика решения учебно-воспитательных задач. - Кострома: КГУ, 1994. - С. 105.

9. Тулькибаева Н.Н. Проблема инновационной деятельности//Инновационные процессы в образовании. - Челябинск.: Образование, 2004. - С. 3-7

10. Хуторской А.В. Педагогическая инноватика: Учеб. пособие для студ. высших учеб. заведений. - М.: Издательский центр «Академия», 2008. - С. 212.

11. Шапир М.И. Филология как фундамент гуманитарного знания: Об основных направлениях исследований по теоретической и прикладной филологии // Антропология культуры. Вып. 1: сб. к 75-летию Вяч. Вс. Иванова. - М.: ОГИ, 2002. - С. 57.

12. Щербакова Е.В. Инновационные процессы и тенденции в образовательном процессе // Актуальные вопросы современной педагогики: материалы IV междунар. науч. конф. (г. Уфа, ноябрь 2013 г.). Уфа: Лето, 2013. - С. 21. 